\title{
The Contribution of Healthcare Workers' Knowledge on Use of Integrated Palliative Care Approach in the Management of Chronic and Life Threatening Diseases at Kakamega County Referral Hospital, Kenya
}

\author{
Wekesa $\mathbf{J}^{1} \Varangle$ (i) \\ Okoth $\mathbf{J}^{2}$ \\ Mutai $\mathbf{C}^{3}$ \\ Arudo $\mathbf{J}^{4}$ \\ 'Department of clinical Nursing and Health Informatics, School of Nursing and Midwifery. Masinde Muliro \\ University of Science and Technology, Kenya \\ Email:wekesajohn@yahoo.com \\ ${ }^{2}$ School of Nursing and Midwifery-Masinde Muliro University of Science and Technology, Kenya \\ SSchool of Public Health and Biomedical Sciences, Masinde Muliro University of Science and \\ Technology, Kenya \\ ${ }^{4}$ Masinde Muliro University of Science and Technology, Kenya
}

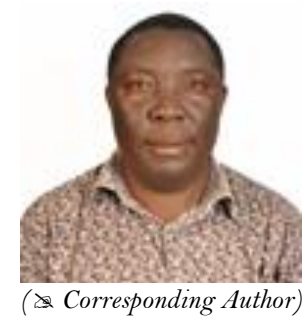

\begin{abstract}
Integrated Palliative care approach (IPCA) is an approach that aims to improve the quality of life of people and their families facing the problems associated with life-threatening illness, through the prevention and relief of suffering. However, the use of IPCA in Kenya is low due to lack of access to medicines, technologies and infrastructure. The main objective was to investigate the use of IPCA in the management of chronic diseases at Kakamega County Referral Hospital (KCRH). The study design was a descriptive cross sectional with the quantitative approach. A questionnaire was administered to participants and the data analysis using SPSS. P-value was set at $<0.05$. Of the total 196 Health Community Workers (HCWs) selected, a response rate of $95 \%$ $(186 / 196)$ was register. It showed that $50 \%$ males were less likely to have used IPCA as compared to their female counterparts $(\mathrm{OR}=0.5,95 \% \mathrm{CI}: 0.3-0.9)$ and $90 \%$ nurses were less likely to practice IPCA as compared to RCOs and MOs (OR=0.1, 95\%CI: 0.1-0.5). The overall hypothesis test on the association between knowledge and performance was not significant $(\mathrm{OR}=1.6 ; 95 \% \mathrm{CI}: 0.7-$ 3.6, $\mathrm{P}<.2$ ). The best managed symptoms by majority of respondents were severe diarrhea, anxiety and depression while the poorly managed areas were pain assessment and treatment of dyspnea. In conclusion, the HCWs were knowledgeable about IPCA but few utilized IPCA in managing terminal illnesses. Therefore, is a need to improve the HCWs' skills and performance, increase funding, and improve infrastructure and coordination of use of IPCA.
\end{abstract}

Keywords: Palliative care, Knowledge, Performance, Healthcare workers, Kenya.

Citation | Wekesa J; Okoth J; Mutai C; Arudo J (2018). The Contribution of Healthcare Workers' Knowledge on Use of Integrated Palliative Care Approach in the Management of Chronic Integrated Palliative Care Approach in the Management of Chronic
and Life Threatening Diseases at Kakamega County Referral Hospital, Kenya. World Scientific Research, 5(1): 24-31. History:

Received: 25 November 2017

Revised: 16 January 2018

Accepted: 22 January 2018

Published: 25 January 2018

Licensed: This work is licensed under a Creative Commons Attribution 3.0 License (co)

Publisher:Asian Online Journal Publishing Group

\section{Contents}

1. Introduction

Contribution/Acknowledgement: All authors contributed to the conception and design of the study.

Funding: This study received no specific financial support

Competing Interests: The authors declare that they have no conflict of interests.

Transparency: The authors confirm that the manuscript is an honest, accurate, and transparent account of the study was reported; that no vital features of the study have been omitted; and that any discrepancies from the study as planned have been explained.

Ethical: This study follows all ethical practices during writing.

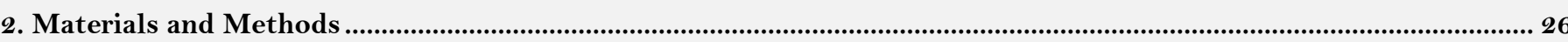

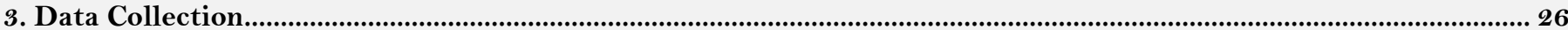

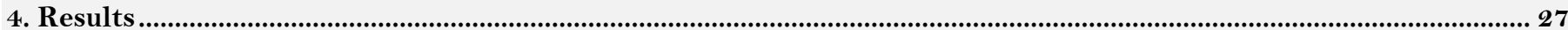

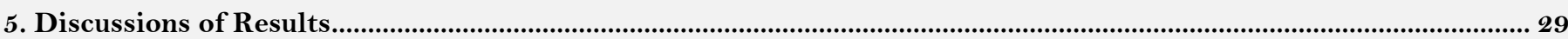

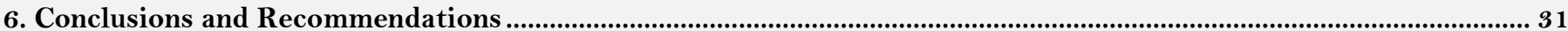

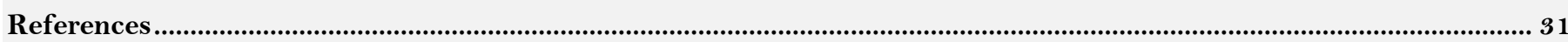

Bibliography 


\section{Introduction}

Palliative Care (PC) is an approach that improves the quality of life of patients and their families facing the problems associated with life-threatening illness through the prevention and relief of suffering by means of early identification, impeccable assessment and treatment of pain and other problems like physical, psychosocial and spiritual" [1].

Use of Integrated palliative care approach occurs at different stages of the illness as demonstrated in the model developed by the oncology service providers. That is as the disease advances, care gradually shifts from a strong focus on disease modifying treatments to a strong focus on care that helps to enhance comfort and maintain function depending on their needs and goals and acknowledging the unpredictability of Death. Integrated palliative care focuses on meeting the physical, psychosocial and spiritual needs of the individual and the family and providing care at appropriate times during an illness in a setting of one's choice [2]. In this regard patients who present early for screening and the diagnosis is made early, palliative care interventions are commenced at diagnosis even though at a minimal level. As the disease modifying interventions or curative care become less effective, use of integrated palliative care approach is increased till such a time when curative interventions will be discontinued and all the focus will be use of integrated palliative care approach. During end of life care and during death and dying, much of integrated palliative care interventions will be symptom management, pain control, cultural issues and ethical issues. Because of family involvement in drawing and implementing the plan of care along the disease trajectory, realistic expectations and anticipations are well managed during grief and bereavement for the diseased family and relatives.

As contained in St. Emanuel's integrated palliative care criteria tool that evaluates the content of the guidelines/pathways regarding the level of PC integration, 11 domains are identified that are used to assess Palliative Care content and include open and honest discussion of the illness limitations and prognosis with the patient and family based on their needs and preferences, enabling shared decision making and holistic assessment. Others are timing of holistic assessment and introducing palliative care, initial and continuous goal adjustment, advance care planning, palliative care team formation and grief and bereavement care [3].

Studies in different settings and disease groups have shown a strong and growing evidence that a palliative approach to care when combined with disease modifying treatment and disease management leads to better outcomes for persons and their family caregivers that includes improvement in symptoms, quality of life and patient satisfaction, less burden on caregivers, more appropriate referral to and use of hospice, and less use of futile intensive care [4].

Spiritual support and pain and symptom management as well as opportunities to revisit his or her goals and care plan (I bid).

\subsection{Health Workers' Knowledge on Use of Integrated Palliative Care Approach Care in the Management of Chronic Diseases}

A correlative survey was carried out among 83 third-year Diploma Nursing students by using cluster sampling method from selected nursing schools of Udupi district, to assess the level of knowledge and attitude of nursing students towards palliative care revealed that the majority $(51 \%)$ of them was in the age group of 21 years and $92 \%$ of them were females. The data showed that $79.5 \%$ of students had poor knowledge $(6.4 \pm 1.64)$ on palliative care and $92.8 \%$ of them had favorable attitude $(56.7 \pm 8.5)$ towards palliative care. The chi-square showed a significant association between knowledge and age $(\chi)=18.52, \mathrm{P}<0.01)$ of the nursing students [5].

In Ethiopia, a similar study by Kassa, et al. [1] showed that Ethiopian nurses had poor knowledge and knowledge aspect of practice on palliative care.

A study in India revealed that nurses and other health care professionals are inadequately prepared to provide pain management and palliative care for patients with chronic diseases as they only demonstrated a biomedical orientation to chronic pain rather than a behavioral one resulting in poor integration of palliative care [6].

In South West Nigerian tertiary hospital, a study on health workers' knowledge and attitude towards Palliative Care clearly showed the followings findings in the following areas: definition of palliative care, $71.8 \%(48 / 66)$ of the respondents understood palliative care to be about pain medicine, $55 \%(33 / 60)$ thought it to be geriatric medicine, while $90.2 \%$ (83/92) felt palliative care is about the active care of the dying. Exactly $80.5 \%(66 / 82)$ respondents agreed that palliative care recognizes dying as a normal process while $84.1 \%(74 / 88)$ respondents were of the opinion that all dying patients would require palliative care. The use of morphine would improve the quality of life of patients according to $68.9 \%(42 / 61)$ of respondents [7].

In Saudi Arabia, a study revealed poor knowledge of nurses about palliative care in the intensive care Unit [8].

The nurses' knowledge on palliative care integration in Ethiopia revealed the followings; knowledge of definition of palliative $70 \%, 82.2 \%$ agreed that Palliative Care is given when patient's conditions are deteriorating. Addiction seen as a major health problem with long term opioid use by $82 \%$ of respondents, (44\%) of the subjects agreed that accumulation of losses render burn out for those who work in Palliative Care. Of the total respondents $69.5 \%, 66 \%$ and $71.6 \%$ agreed that adjuvant therapies are important in pain management, that the patients right not to resuscitate (DNR) should be respected, and that terminally ill patients should be encouraged to have hope, respectively. Again, out of the total study participants only 104 (30.5\%) had good knowledge towards Palliative Care [1].

The study further showed that two thirds (76.2\%) of the respondents had poor knowledge towards Palliative Care with only $54.2 \%$ of them initiating PC discussions with patients during diagnosis while 167 (49\%) of nurses informing terminally ill patients about their diagnosis. Regarding decision making, 205 (60.1\%) of the respondents reported obtaining patients' opinions and $111(32.6 \%)$ involved the family in the decision making amongst the family. Regarding psychological issues of the patient, 285 (83.6\%) of respondents reported hiding the truth from patients, $180(52.8 \%)$ preferred to give emotional support, and $159(46.6 \%)$ provided counseling to the patients. The majority (96.8\%) of the respondents perceived terminally ill patients concern as need of treatment and 307 (90\%) had attention seeking behavior, respectively. The commonly used medications for severe pain were paracetamol or 
ibuprofen 207 (60.7\%), morphine 108 (31.1\%) and codeine 41 (12\%).Respondents mentioned that Palliative Care was provided most to patients with cancer (36.4) and HIV (28.4\%) (Ibid).

\section{Materials and Methods}

\subsection{Study Site}

Kakamega County Referral Hospital, Kakamega County, Lurambi Sub county 1/2 kilometer form Kakamega town on Kisumu webuye highway western region of western Kenya.

\subsection{Study Design}

Descriptive cross sectional study.

\subsection{Study Population}

Healthcare workers; Nurses, Clinical officer who work in departments that deal with care of patients with chronic and life threatening diseases between the periods of July 2016 to July 2017.

\subsection{Inclusion and Exclusion Criteria}

\subsubsection{Inclusion Criteria}

Healthcare workers who have been employed for at least 3months, working in the departments that deal chronic illnesses were included since they were deemed to be familiar and experienced with the care of patients with chronic and life threatening illnesses.

\subsection{Exclusion Criteria}

Those who were not working in departments dealing with chronic diseases will be excluded as they considered unfamiliar and inexperienced in caring for patients with chronic and life threatening illnesses./1 before commencement of chemotherapy

\subsection{Sampling Technique}

Using fisher's method (2003) a sample size of 196 healthcare workers; nurses, clinical officers and medical officers from a target population of 330 were proportionately allocated to their numerical strength as follows(nurses 174(52.7\%),clinical officers 98(29.6\%) and medical officers 58(17.7\%). Source: Kakamega county referral hospital personnel office (2015).the sampling strategy 196 HCWs namely nurses, clinical officers and doctors were drawn from various departments that deal with patients suffering from chronic and life threatening diseases in the hospital; namely medical wards, gynecological ward, outpatient department, comprehensive care Centre, oncology and palliative care clinic. Using the list of names of staffs in each professional cadre and department in which they were deployed, the researcher applied the Statistical Product and Services Software (SPSS) to randomize and get the respondents in each category to be interviewed (103 nurses; 58 clinical officers and 35 Medical officers).

The independent variables were socio demographic characteristics, knowledge, performance and factors influencing utilization of integrated palliative care approach in the management of chronic and life threatening diseases, confounding variables were policies on opioid use, infrastructure and health financing and allocation for palliative care services while the dependent variable was performance of health care workers on utilization of integrated palliative care by healthcare workers in the management of chronic and life threatening diseases (Those who cared for patients with chronic illnesses within 6-12 months during the study period applying Palliative care approach) and those who observed demonstrating use of domains of palliative care in the care of patients with chronic and life threatening illnesses.

\section{Data Collection}

Data was collected using interviewer semi structured questionnaires and observational checklist.

\subsection{Data Collection Tools}

Semi-Structured questionnaires adopted and modified from that used by Chidiebere [9] was used. The questionnaire had four sections as follows; The first section had the socio-demographic characteristics of healthcare workers; the second part assessed the health workers' knowledge on use of integrated palliative care approach while the third part determined the healthcare workers performance on utilization of integrated palliative care approach in the management of chronic diseases. The fourth part was to determine the factors influencing the utilization of integrated palliative care approach in the management of chronic diseases. The observation checklist, the health care workers performance of palliative care scale(HCWPPCS) adapted and modified from Warda, et al. [10] which had 8 items that palliative care performance was measured .It covers the areas related to physical symptom such as pain, nausea and vomiting, dyspnea, severe diarrhea and anorexia and psychological symptoms such as anxiety, insomnia and depression.

Observation of health care workers during their practices was done during working hours when they were with the patients in their respective areas of work. The researcher and the trained assistants observed each health worker once after data collection by the questionnaire was done.

\subsection{Data Collection Procedure}

Validated semi-structured questionnaires and observational checklist were used to collect relevant data for the study from the sampled respondents comprising of nurses, clinicians and doctors was conducted by the researcher and trained assistant. Data collection started with self-introduction and overview of the research including the study objectives. The respondents were not required to write their names. Explanations were given to respondents as required. Data was collected relating to demographics, professional characteristics, health workers practice, 
knowledge towards palliative care integration in the management of chronic illnesses and barriers to palliative care integration. Demographic data included age, gender and religious affiliations. Professional characteristics included the type of ward/departments or Unit, professional cadre, highest level of education attained, employment status, role, years of work experience, and duration of work in the unit and hospital and previous palliative care training. In regard to the observational checklist, data was collected how health workers addressed the symptoms that affected the quality of life of the patient and their families.

\subsection{Reliability of the Study Tools}

A Pilot study was carried out on a similar population, that is, in Webuye county referral hospital using testre'test method for the purpose of estimating the length of the interview and research assistants to familiarize with interview process. The same tools were used and with (10\%) respondents at two different points in time within an interval of two weeks. The Cronbach's alpha coefficient of 0.71 was achieved and hence accepted for reliability of the tool. Study data tools were checked for consistency and relevance by researchers, Lectures and Supervisors. Recruitment of three research assistants' were selected from the healthcare workers in the study area and their training was done in three days in an attempt to minimize error and bias during the interview process.

\subsection{Validity of the Study Tools}

Content validity was measured by using the Content Valid Index (CVI), where relevant items in relation to the research objectives in the questionnaire were rated by the assessors in Masinde Muliro University of science and Technology. Validity was tested as follows: CVI=Relevant Items/Total Number of Items. The test results of the CVI were 0.74 which was within the acceptable limits hence the tool was valid. The supervisors' comments were incorporated in the final instruments.

\subsection{Data Management and Analysis}

Collected data from the study was thoroughly checked and validated for accuracy and completeness. The data was stored in electronic formats and hard copies. Data collecting tools were kept in lockable cabinets that had authorized access. It was only directly accessible only to the investigators. Data from the tool was coded, cleaned and entered into a computer software; Statistical Package for Social Science (SPSS) version 20.

Logistic regression and Odds ratio were used to determine the significance and the magnitude of association between the independent variables (socio-demographic characteristics, the healthcare workers' knowledge, and the dependent variablehealthcare workers' performance on the use of integrated palliative care approach in the management of chronic and life threatening diseases. Chi-square used to calculate hypothesis. Results with a pvalue of equal or more than 0.05 was considered significant. To assess the healthcare workers knowledge on palliative care integration ,the respondents were given 15,5 point Likert Scale true statements to respond to 1Strongly Disagree, 2-Disagree, 3-Don't Know,4-Agree and 5-Strongly Agree. The knowledge of the healthcare workers on palliative care integration was based on the palliative care domains and constituted general and specific knowledge on use of integrated palliative care approach.

Health care workers' performance on using integrated palliative care approach was taken as the outcome of interest. That is the respondents who cared for patients with chronic and life threatening illnesses using integrated palliative care approach within the last 6-12months during the study period were considered to have had integrated palliative care approach. The use of integrated palliative care approach involved addressing the physical, spiritual, psychological, social, and ethical and symptom management. Those who provided care to patients using integrated palliative care approach were considered to have had good performance in use of integrated palliative care approach and those who provided care for patients for more than 20 patients per month, addressing most or all of the domains of palliative care with initiation of the care early in the illness were considered to have had a good practice as compared to those who cared for less than 20 patients per month or none. The results were presented in pie charts, bar graphs and tables.

\subsection{Ethical Considerations}

In conducting the study, the researcher adhered to the ethical and legal guidelines and ensured that the respondents' human rights were safeguarded. Permission was sought from the Institutional Review and Ethics Committee (IREC) so as to enable the researcher carry out the study. A letter of approval from the Dean, School of Graduate Studies and the NACOSTI research permit and the guidelines and the hospital administration were used in conducting a research. The election of respondents was based on the ethical principle of justice which stresses fair treatment of subjects in the study. The respondents were selected randomly from each discipline using SPSS. The respondents' participation was voluntary. Their consent to participate or decline was sought throughout the exercise.

The participant was free to withdraw at any stage of the study. This was based on the ethical principle of respect for persons; people should be treated as autonomous agents; the prospective respondents were given all the necessary information and time to process and decide whether or not to participate in the study. Respondents were free to withdraw from the study without penalty. No data was collected from the respondent who explicitly refused to participate. The researcher sought the informed consent from participants who read, understood and signed the consent form in Appendix III.

\section{Results}

\subsection{The Study Sought to Determine the Healthcare Workers' General Knowledge on Use of Integrated Palliative Care in the Management of Chronic and Life Threatening Diseases}

The respondents were given 15,5 point Likert Scale true statements to respond to 1-Strongly Disagree, 2Disagree, 3-Don't Know,4-Agree and 5-Strongly Agree. For purposes of convenience, know, agree and strongly 
agree were combined to be represented by agree, while strongly agree, disagree and don't know were combined to be represented by disagree.

The results were as follows; the health workers' knowledge in regard to domains on IPCA was assessed based on six (6) statements which required respondents to state whether they agreed or disagreed with the statement. Majority (98.4\%) correctly agreed that IPCA focuses on physical, psychological, spiritual issues, medical decisionmaking and on relief of suffering in all its dimensions throughout a person's life. Nearly one in five (19.3\%) incorrectly stated that IPCA is only appropriate in situations of a downhill trajectory or deterioration in conditions. The response on provision of IPCA requiring emotional attachment received almost comparable proportions with $48.4 \%$ agreeing and $51.6 \%$ disagreeing. Most of the respondents $(58.1 \%)$ disagreed with the statement that the philosophy of IPCA is compatible with that of aggressive treatment during end of life stage. An overwhelming proportion agreed that the accumulation of losses renders burnout which is inevitable for those who work in palliative care set up. As regards the statement that terminally ill patients have the right to choose "Do not resuscitate” also referred to as DNR, 83.9\% disagreed.

Table-4.1. Health workers general knowledge on integrated palliative care approach in the management of chronic and life threatening diseases.

\begin{tabular}{|c|c|c|}
\hline \multirow[t]{2}{*}{ General knowledge items } & Agree & Disagree \\
\hline & $\mathrm{N}(\%)$ & $\mathrm{N}(\%)$ \\
\hline $\begin{array}{l}\text { Integrated palliative care focuses on physical issues, psychosocial issues, spiritual matters, medical } \\
\text { decision-making and on relief of suffering in all its dimensions throughout a person's illness. }\end{array}$ & $\begin{array}{l}183 \\
(98.4)\end{array}$ & $\begin{array}{l}3 \\
(1.6)\end{array}$ \\
\hline $\begin{array}{l}\text { Integrated Palliative care is only appropriate in situations of a downhill trajectory or deterioration } \\
\text { in conditions. }\end{array}$ & $\begin{array}{l}36 \\
(19.3)\end{array}$ & $\begin{array}{l}150 \\
(80.7)\end{array}$ \\
\hline The provision of integrated palliative care approach requires emotional attachment & $\begin{array}{l}90 \\
(48.4)\end{array}$ & $\begin{array}{l}96 \\
(51.6)\end{array}$ \\
\hline $\begin{array}{l}\text { The philosophy of palliative care is compatible with that of aggressive treatment during end of life } \\
\text { stage. }\end{array}$ & $\begin{array}{l}78 \\
(41.9)\end{array}$ & $\begin{array}{l}108 \\
(58.1)\end{array}$ \\
\hline The accumulation of losses renders burnout inevitable for those who work in palliative care set up. & $\begin{array}{l}159 \\
(85.5)\end{array}$ & $\begin{array}{l}27 \\
(14.5)\end{array}$ \\
\hline Terminally ill patients have the right to choose "Do not resuscitate" (DNR). & $\begin{array}{l}30 \\
(16.1)\end{array}$ & $\begin{array}{l}156 \\
(83.9)\end{array}$ \\
\hline
\end{tabular}

\subsection{Health Workers Knowledge on the Correct Performance on Use of Integrated Palliative Care Approach in Managing Chronic and Life Threatening Diseases}

Majority (95.2\%) correctly confirmed that the extent of the disease determines the method of pain treatment. The same applied to $77.4 \%$ who affirmed that adjuvant therapies are important in managing pain. Most of the respondents $(71 \%)$ disagreed that long term use of opioid medications should be avoided in long term pain management. In the same way, $72.6 \%$ disagreed with the statement that during terminal stages of an illness, opioid drugs should be avoided as they cause respiratory depression in patients with COPD. However, the use of placebos being appropriate in the treatment of some types of pain drew mixed responses with $50 \%$ agreeing and $50 \%$ disagreeing. Majority agreed that WHO's pain management golden rules are 'by the mouth, by the clock and by the ladder.' In this regard, 95.2\% agreed that WHO's step ladder for pain management is the most recommended approach in managing various intensities of pain. Ninety-two percent correctly stated that manifestations of chronic pain are different from those of acute pain. An even larger proportion (96.8\%) agreed that prior assessment of patients using standardized tools for pain intensity is important to decide the type of analgesics used.

Table-4.2. Health workers knowledge on the correct practice of integrated palliative care $\mathrm{N}=186$ )

\begin{tabular}{|c|c|c|}
\hline \multirow[t]{2}{*}{ Statements of health workers' knowledge on correct practice of IPCA } & Agree & Disagree \\
\hline & $\mathrm{N}(\%)$ & $\mathrm{N}(\%)$ \\
\hline The extent of the disease determines the method of pain treatment & $\begin{array}{l}177 \\
(95.2)\end{array}$ & $\begin{array}{l}9 \\
(4.8)\end{array}$ \\
\hline Adjuvant therapies are important in managing pain. & $\begin{array}{l}144 \\
(77.4) \\
\end{array}$ & $\begin{array}{l}42 \\
(22.6) \\
\end{array}$ \\
\hline $\begin{array}{l}\text { Long term use of opioid medications should be avoided in long term pain management as they can } \\
\text { cause drug addictions to the terminally ill patients. }\end{array}$ & $\begin{array}{l}54 \\
(29.0)\end{array}$ & $\begin{array}{l}132 \\
(71.0)\end{array}$ \\
\hline $\begin{array}{l}\text { During the terminal stages of an illness, opioid drugs should be avoided as they can cause } \\
\text { respiratory depression in patients with COPD have severe dyspnea }\end{array}$ & $\begin{array}{l}51 \\
(27.4)\end{array}$ & $\begin{array}{l}135 \\
(72.6)\end{array}$ \\
\hline The use of placebos is appropriate in the treatment of some types of pain. & $\begin{array}{l}93 \\
(50.0) \\
\end{array}$ & $\begin{array}{l}93 \\
(50.0) \\
\end{array}$ \\
\hline WHO's pain management golden rules are by the mouth, by the clock and by the ladder & $\begin{array}{l}183 \\
(98.4)\end{array}$ & $\begin{array}{l}3 \\
(1.6)\end{array}$ \\
\hline Manifestations of chronic pain are different from those of acute pain. & $\begin{array}{l}171 \\
(91.9)\end{array}$ & $\begin{array}{l}15 \\
(8.1)\end{array}$ \\
\hline $\begin{array}{l}\text { Prior assessment of patients using standardized tools for pain intensity is important to decide the } \\
\text { type of analgesics to be given. }\end{array}$ & $\begin{array}{l}180 \\
(96.8)\end{array}$ & $\begin{array}{l}6 \\
(3.2)\end{array}$ \\
\hline $\begin{array}{l}\text { WHO's step ladder for pain management is the most recommended approach in managing various } \\
\text { intensities of pain? }\end{array}$ & $\begin{array}{l}177 \\
(95.2)\end{array}$ & 9 \\
\hline
\end{tabular}

Source: data analysis

\subsection{Bivariate Analysis on the Association between Knowledge on IPCA and Health Workers Performance on Use of IPCA at Workplace}

Concerning knowledge on IPCA and health workers having practiced IPCA within the last $6-12$ months, knowledge on when to practice IPCA in situations of downhill trajectory or deterioration in condition and that accumulation of losses render burnout inevitable for those who work in palliative care set up were statistically 
associated with the outcome. A significantly higher proportion of those who agreed that IPCA was only appropriate in situations of downhill trajectory or deterioration in condition were 2 -fold more likely to have provided care to patients using IPCA within the last 6-12 months (OR=2.3, 95\% CI: $1.1-5.0 \mathrm{P}=0.026)$. Similarly, those who agreed that accumulation of losses render burnout inevitable for those who work in palliative care set up were 10 times more likely have practiced IPCA within the last $6-12$ months (OR=10.4, 95\% CI: $3.0-$ $36.1 \mathrm{p},<0.0001)$.

Table-4.3. Bivariate analysis on the association between knowledge on IPCA and health workers performance of IPCA at workplace

\begin{tabular}{|c|c|c|c|c|c|}
\hline \multirow[t]{2}{*}{ Risk factor } & \multicolumn{5}{|c|}{$\begin{array}{l}\text { Practices integration of } \\
\text { palliative care approach }\end{array}$} \\
\hline & $\begin{array}{l}\text { Yes } \\
\mathrm{N}=93 \\
(\%)\end{array}$ & $\begin{array}{l}\text { No } \\
\mathrm{N}=\mathbf{9 3} \\
(\%)\end{array}$ & $\begin{array}{l}\text { Overall } \\
\text { OR }\end{array}$ & $95 \%$ CI & $P$ value \\
\hline \multicolumn{6}{|l|}{$\begin{array}{l}\text { IPCA only appropriate in situations of downhill } \\
\text { trajectory or deterioration in condition }\end{array}$} \\
\hline Agree & 66.7 & 33.3 & \multirow[t]{2}{*}{2.3} & \multirow[t]{2}{*}{$1.1-5.0$} & \multirow[t]{2}{*}{0.026} \\
\hline Disagree & 46.0 & 54.0 & & & \\
\hline \multicolumn{6}{|l|}{$\begin{array}{l}\text { Accumulation of losses render burnout } \\
\text { inevitable for those who work in palliative care } \\
\text { set up }\end{array}$} \\
\hline Agree & 56.6 & 43.4 & \multirow[t]{2}{*}{10.4} & \multirow[t]{2}{*}{$3.0-36.1$} & \multirow[t]{2}{*}{$<0.0001$} \\
\hline Disagree & 11.1 & 88.9 & & & \\
\hline
\end{tabular}

Source: research findings

\subsection{Bivariate Analysis on the Association between Knowledge on Management of Patients with Terminal Illness and Health Workers Performance of IPCA at Workplace}

Three independent factors on knowledge on management of patients with terminal illness were independently associated with the practice of IPCA within the last 6-12 months. Knowledge on the fact that adjuvant therapies are important in pain management, non-avoidance of long term use of opioid medications in management of pain and use of placebo being appropriate in the treatment of some types of pain were significantly associated with the outcome. Respondents who said that the extent of the disease determines the method of pain treatment were 48 times more likely to practice or use IPCA in the management of chronic diseases (OR=47.5, 95\% CI: $1.2-366.7$ $\mathrm{P}=0.002)$. Respondents who said that adjuvant therapies are important in pain management were 3 times more likely to have practiced IPCA (OR=3.2, 95\% CI: $1.5-6.8, \mathrm{P}=0.002)$. On the contrary, respondents who stated that long term use of opioid medications should be avoided in pain management for those with terminal illness were $50 \%$ less likely to have practiced IPCA $(\mathrm{OR}=0.5,95 \% \mathrm{CI}: 0.3-1.0, \mathrm{P}=0.05)$. The result was significant at $\mathrm{p}=0.05$. Likewise, respondents who said that placebo is appropriate in the treatment of some types of pain were $70 \%$ less likely to have practiced IPCA within the same period referenced ( $\mathrm{OR}=0.3,95 \% \mathrm{CI}$ : $0.2-0.6, \mathrm{P}=<0.0001)$.

Table-4.4. Bivariate Analysis on the Association between Knowledge on Management of Patients with Terminal Illness and Health Workers Performance of IPCA at Workplace

\begin{tabular}{|c|c|c|c|c|c|}
\hline \multirow[t]{2}{*}{ Risk factor } & \multicolumn{2}{|c|}{$\begin{array}{l}\text { Practices integration } \\
\text { palliative care approach }\end{array}$} & \multirow[b]{2}{*}{ Overall OR } & \multirow[b]{2}{*}{$95 \% \mathrm{CI}$} & \multirow[b]{2}{*}{$\mathrm{P}$ value } \\
\hline & $\begin{array}{l}\text { Yes } \\
\mathrm{N}=93(\%)\end{array}$ & $\begin{array}{l}\text { No } \\
\mathrm{N}=93(\%)\end{array}$ & & & \\
\hline \multicolumn{6}{|c|}{$\begin{array}{l}\text { The extent of the disease determines the method of pain } \\
\text { treatment }\end{array}$} \\
\hline Agree & 52.5 & 47.5 & \multirow[t]{2}{*}{21.0} & \multirow{2}{*}{$\begin{array}{ll}1.2- \\
366.7\end{array}$} & \multirow[t]{2}{*}{0.002} \\
\hline Disagree & 0.0 & 100.0 & & & \\
\hline \multicolumn{6}{|c|}{ Adjuvant therapies are important in managing pain } \\
\hline Agree & 56.3 & 43.7 & \multirow[t]{2}{*}{3.2} & \multirow[t]{2}{*}{$1.5-6.8$} & \multirow[t]{2}{*}{0.002} \\
\hline Disagree & 28.6 & 71.4 & & & \\
\hline \multicolumn{6}{|c|}{$\begin{array}{l}\text { Long term use of opioid medications should be avoided in long } \\
\text { term pain management }\end{array}$} \\
\hline Agree & 38.9 & 61.1 & \multirow[t]{2}{*}{0.5} & \multirow[t]{2}{*}{$0.3-1.0$} & \multirow[t]{2}{*}{0.05} \\
\hline Disagree & 54.6 & 45.4 & & & \\
\hline \multicolumn{6}{|c|}{$\begin{array}{l}\text { Use of placebo is appropriate in the treatment of some types of } \\
\text { pain }\end{array}$} \\
\hline Agree & 35.5 & 64.5 & \multirow[t]{2}{*}{0.3} & \multirow[t]{2}{*}{$0.2-0.6$} & \multirow[t]{2}{*}{$<0.000$} \\
\hline Disagree & 64.5 & 35.5 & & & \\
\hline
\end{tabular}

Source: research findings

Testing hypothesis association between knowledge and performance

There is no association between knowledge about integrated palliative care approach and performance in IPCA $(\mathrm{OR}=1.6 ; 95 \% \mathrm{CI}: 0.7-3.6, \mathrm{P}<.2316)$.

\section{Discussions of Results}

The results also revealed that most respondents were males. Males were $50 \%$ less likely to practice IPCA compared to their female counterparts $(\mathrm{OR}=0.5,95 \% \mathrm{CI}: 0.3-0.9)$. This could probably be due to the cultural influence to the caring attitudes males could have towards those with terminal illnesses. Interestingly, nurses were $90 \%$ less likely to practice IPCA compared to clinical officers and medical doctors (OR=0.1, 95\% CI: 0.1 - 0.3). This could be probably due to the nurses' role having been masked by competing tasks and their tendency to take a subordinate role in carrying out the clinician's instructions and non-prescriptive roles when it comes to opioid pain medications that are normally done by clinical officers and doctors. The results also showed that healthcare workers who had cared for patients with terminal illness for less than 20 months were $80 \%$ less likely to have 
practiced IPCA within the last 6-12 months. On the other hand, those who had worked in the facility for less than 10 years were 3 times more likely to practice IPCA (OR=3.2, 95\% CI: $1.5-6.8)$ indicating that they still youthful, energetic and highly educated compared to those that had worked in the same facility for over 10years who could be old, tired and less motivated. All the associations were statistically significant.

Nearly half of the medical personnel interviewed at 90(48.4\%) worked at the surgical department, 69(37.1\%) in the medical department, 18(9.7\%) in other departments apart from those mentioned above while the least at $9(4.8 \%)$ deployed in outpatient department. This diversity was critical in giving representative views on integrated palliative care as each department played a unique yet critical role in caring for the patients though there was no significant association with practice.

The clinical officers were $4.857(\mathrm{p}=.005)$ times more likely to manage chronic diseases through palliative care as compared to medical officers. This could be due to their availability in most places where they served as first line clinicians to attend to patients and clients before medical officers can attend to them.

In line with first objective; health workers' knowledge on use of integrated palliative care approach; Concerning knowledge on IPCA and health workers having practiced IPCA within the last $6-12$ months, knowledge on when to practice IPCA in situations of downhill trajectory or deterioration in condition and that accumulation of losses render burnout inevitable for those who work in palliative care set up were statistically associated with the outcome. A significantly higher proportion of those who agreed that IPCA was only appropriate in situations of downhill trajectory or deterioration in condition were 2 -fold more likely to have practiced IPCA within the last 6-12 months (OR=2.3, 95\% CI: $1.1-5.0$ ) probably due the fact that many people wrongly understand palliative care being suitable only at the end of life period. Despite the fact that majority who agreed with this statement were likely to have practiced IPCA, they would delay interventions to relieve pain and prevent suffering. These results are in divergence with the study by Glare and Virik [11] whose findings stated that palliative care should be available early in the course of a disease whose findings showed that both national and international societies highly recommend early integration of palliative care approach for better patient outcomes. Similarly, those who agreed that accumulation of losses render burnout inevitable for those who work in palliative care set up were 10 times more likely have practiced IPCA within the last $6-12$ months $(\mathrm{OR}=10.4,95 \% \mathrm{CI}: 3.0-$ 36.1), showing that those with the correct knowledge and sometimes experienced burnouts in the course of their work were likely to influence the provision of quality palliative care. This concurs with Kassa, et al. [1] whose study on nurses' knowledge on palliative care revealed that $85.5 \%$ of respondents agreed with a similar statement.

Three independent factors on knowledge on management of patients with terminal illness were independently associated with the practice of IPCA within the last $6-12$ months. Knowledge on the fact that adjuvant therapies are important in pain management, avoidance or non-avoidance of long term use of opioid medications in management of pain and use of placebo being appropriate in the treatment of some types of pain were significantly associated with the outcome. Respondents who (77.4\%) correctly said that adjuvant therapies are important in pain management were 3 times more likely to have practiced IPCA (OR=3.2, 95\% CI: $1.5-6.8)$ since they had had knowledge and experience in their use. This was in line with Kassa, et al. [1] whose study showed similar findings. On the contrary, respondents $(71 \%)$ who stated that long term use of opioid medications should be avoided in pain management for those with terminal illness were $50 \%$ less likely to have practiced IPCA (OR=0.5, 95\% CI: 0.3 1.0). This could be due to their lack of correct knowledge on opioid medications that made them avoid managing pain. The result was significant at $\mathrm{p}=0.05$.Likewise, respondents $(83.9 \%)$ who disagreed with the statement that placebo is appropriate in the treatment of some types of pain were $70 \%$ less likely to have practiced IPCA within the same period referenced ( $\mathrm{OR}=0.3,95 \% \mathrm{CI}$ : $0.2-0.6)$ probably due to lack of knowledge on various methods of managing various types of pain. This is echoed by the findings by Kassa, et al. [1] but disagreed with the findings of a study in the USA by Amir, et al. [12] which revealed that (45\%) of the physicians surveyed reported administering placebos, with $(96 \%)$ believing that placebos have a therapeutic effect. The result was significant at $\mathrm{p}$ $=0.05$. Generally majority $(98.4 \%)$ of the respondents correctly agreed that IPCA focuses on physical, psychological, spiritual issues, medical decision-making and on relief of suffering in all its dimensions throughout a person's life. This is also in agreement with Kassa, et al. [1] among the Ethiopian health workers although the study was limited to only few domains of palliative care. Bakitas, et al. [2] have similar findings.

Nearly one in five (19.3\%) incorrectly stated that IPCA is only appropriate in situations of a downhill trajectory or deterioration in conditions. This was probably due to lack of correct knowledge. This finding though is represented by few respondents' correlates well with a related study in Nigeria by Fadare, et al. [7] and 2016 which showed poor knowledge of health care workers on palliative care and that 90\% respondents saying palliative care is the active care of those who are dying but diverges from other study by Glare and Virik [11] whose results emphasized on early integration of palliative care approach for better patient outcomes and improved quality of life of patients and their families. Most of the respondents (58.1\%) disagreed with the statement that the philosophy of IPCA is compatible with that of aggressive treatment during end of life stage. This is in agreement with Koesel [13] which states that many providers recommend support of the patient and family into accepting a peaceful endof-life experience and foregoing life-prolonging treatments. This is however different from the findings of Jox, et al. [14] which stated that aggressive interventions during end of life care is still being practiced despite it having been known to be non-beneficial to the patient.

An overwhelming proportion agreed that the accumulation of losses renders burnout which is inevitable for those who work in palliative care set up. This is also reflected in a study in Ethiopia by Kassa, et al. [1] that had $44 \%$ of respondents agreeing that accumulation of loses rendered frequent burnout to those work in palliative care set up. As regards to the statement that terminally ill patients have the right to choose "Do not resuscitate" also referred to as DNR, $83.9 \%$ disagreed. Similarly Kassa, et al. [1] arrived to same findings indicating that most health care workers lacked knowledge on ethical issues regarding end of life care and are likely to abuse the rights of the recipients of their care.

From the study majority (95.2\%) of respondents where knowledgeable on correct practice on IPCA as they agreed with the statement " the extent of the disease determines the method of pain treatment", $77.4 \%$ affirming the importance of use of adjuvant therapies in managing pain. This is true because according to WHO's step ladder, 
mild pain is treated with non-opioid analgesics while strong pain is managed by strong opioids and adjuvant medications. This finding differ from that of Zahra, et al. [8] in Saudi Arabia which revealed that nurses working in the intensive care unit had poor knowledge about palliative care.

\section{Conclusions and Recommendations}

\subsection{Conclusions}

Health care workers were knowledgeable about integrated palliative care approach. The study established that HCWs performed integrated palliative care approach but being performed well by only few. However, there are significant caps needs to be addressed to improve the HCWs' knowledge and performance. This includes: increasing funding, improving infrastructure and coordinating of use of IPCA HCWs' performance at Kakamega County Referral Hospital. This is because IPCA is particularly needed in places where a high proportion of patients present in advanced stages and there is little chance of cure.

The identified factors that influence palliative care integration included; lack of knowledge on pain and symptom management, inadequate communication between staff, patients and their families and inadequate research on palliative care activities. Therefore, education and training of health professionals in palliative care should be provided by medical and nursing schools throughout the country.

The study also reveals that majority of the respondents had poor performance despite exhibiting high knowledge hence the null hypothesis that there is no relationship between knowledge and performance. Therefore, close collaboration between medical and nursing associations to achieve this end will be needed.

\subsection{Recommendations}

There is need for the County government of Kakamega together with the management of Kakamega County Referral Hospital to carry out the following interventions:

Train more HCWs at the Hospital on use of integrated palliative care approach in the management of chronic diseases to enhance their knowledge and performance.

Allocate more funds, improve infrastructure, and strengthen coordination and referral structures, address shortage in staffing. There is also need to improve health worker motivation, strengthen communication with staff as well as prioritize research to enhance learning and allocate funds for further research in palliative care and other related fields.

\section{References}

[1] H. Kassa, R. Murugan, F. Zewdu, M. Hailu, and D. Woldeyohannes, "Assessment of knowledge, attitude and practiceand associated factors towards palliative care among nurses working in selected hospitals, Addis Ababa, Ethiopia," BMCPalliat Care, vol. 13, p. 6, 2014. View at Google Scholar | View at Publisher

[2] M. Bakitas, K. Lyons, and M. Hegel, "Effects of a palliative care intervention on Clinical outcomes in patients with advanced cancer: The Project ENABLE II randomized control trial," JAMA, vol. 302, pp. 741-749, 2015. View at Google Scholar $\mid$ View at Publisher

[3] V. B. Karen, N. Siouta, N. Preston, J. Hasselaar, Hughess, P. Payne, L. Radbruch, C. Centeno, A. Csikos, E. Garralda, E. Marlieke, F. Hodiamont, I. Radvanyi, and J. Menten, "To what degree is palliative care integrated in guidelines and pathways for adult cancer patients in Europe: A systematic literature review," Biomedical Central Palliative Care, vol. 15, p. 26, 2016. View at Google Scholar | View at Publisher

[4] C. B. Smith, J. E. Nelson, A. R. Berman, C. A. Powell, J. Fleischman, J. Salazar-Schicchi, and J. P. Wisnivesky, "Lung cancer physicians' referral practices for palliative care consultation," Annals of Oncology, vol. 23, pp. 382-387, 2012. View at Google Scholar | View at Publisher

[5] L. Harazneh, A. Ayed, Fahafsheh, and A. G. El-Nasser, "Knowledge of palliative care among bachelors nursing students," Journal of Health, Medicine and Nursing, vol. 18, pp. 25-32, 2015. View at Google Scholar

[6] V. Prem, H. Karvannan, S. P. Kumar, S. Karthikbabu, N. Syed, V. Sisodia, and S. Jaykumar, "Study of nurses' knowledge about palliative care: A quantitative cross-sectional survey," Indian Journal on Palliative Care, vol. 18, pp. 122-127, 2012. View at Google Scholar $\mid$ View at Publisher

[7] J. Fadare, M. Abimbola, M. Afolayan, S. Popoola, A. 3Tolulope, and P. Adegun, "Healthcare workers knowledge and attitude toward palliative care in an emerging tertiary centre in South-West Nigeria," Indian Journal of Palliative Care, vol. 20, pp. 1-5, 2014. View at Google Scholar | View at Publisher

[8] A. Zahra, A. Mohamad, T. Sormunen, and E. Hilleras, "Nurses knowledge about palliative care in an intensive care unit in Saudi Arabia," Middle East Journal of Nursing, vol. 9, pp. 7-13, 2015. View at Google Scholar

[9] M. I. Chidiebere, "Factors influencing cervical cancer screening uptake among women attending Mahalapye District Hospital in Botswana.use of health belief model," International Journal of Women's Health, vol. 7, pp. 31-39, 2009.

[10] Y. M. M. Warda, G. H. Eskander, H. A. Ahmed, and Elfeky, "Intensive care nurses' knowledge \& practices regarding Infection control standard precautions at a selected Egyptian cancer hospital," Journal of Education and Practice, vol. 4, 2013. View at Google

[11] P. Sholar $\quad$ Glare and K. Virik, "Can we do better in End-of-life care? The mixed management model and palliative care," Medical Journal of Australia, vol. 175, pp. 530-533, 2001. View at Google Scholar

[12] R. Amir, E. Raikhel, and D. A. Ran, "Placebos in medicine: Knowledge, beliefs and patterns of Use," McGill Journal of Medicine, vol. 11, pp. 206-2 1 1, 2008. View at Google Scholar

[13] N. M. Koesel, "Conflicts in goals of care at the end of life: Are aggressive life-prolonging interventions and a "Good Death" compatible?," Journal of Hospice \& Palliative Nursing, vol. 16, pp. 330-335, 2014. View at Google Scholar $\mid$ View at Publisher

[14] M. Jox, Š. Lenko, and P. Ivana, "Futile treatment-a review," Journal of Bioethical Inquiry, vol. 14, pp. 329-337, 2017. View at Google Scholar | View at Publisher

\section{Bibliography}

[1] A. Ahmad, S. Sayej, L. Harazneh, and I. Fashafsheh, "The nurses' knowledge and attitudes towards the palliative care," Journal of Education and Practice, vol. 6, pp. 2222-288, 2015. View at Google Scholar

[2] A. Zahra, A. Mohamad, T. Sormunen, and E. Hilleras, "Nurses knowledge about palliative care in an intensive care unit in Saudi Arabia," Middle East Journal of Nursing, vol. 9, pp. 7-13, 2015. View at Google Scholar

[3] S. Butola, "A study on knowledge, attitude, and practices regarding palliative care among doctors in border security force, India," Journal of Palliative Care, vol. 22, pp. 272-279, 2014. View at Google Scholar $\mid$ View at Publisher 